\title{
The Crystal and Molecular Structure of a Dibromo-derivative of MS-3: a Glyoxalase I Inhibitor Produced by a Mushroom, Stereum hirsutum
}

\author{
Hikaru Nakamura, Yoichi IItaka, Shyogo Kurasawa,* \\ Tomio TAKEUCHI ${ }^{*}$ and Hamao UMEZAWA* \\ Faculty of Pharmaceutical Sciences, University of Tokyo, Bunkyo-ku, Tokyo, Japan \\ *Institute of Microbial Chemistry, Kamiosaki, Shinagawa-ku, Tokyo, Japan
}

Received March 23, 1976

\begin{abstract}
X-Ray structure determination of a dibromo-derivative of MS-3, a glyoxalase I inhibitor produced by a mushroom, was carried out by the heavy atom method. A total of 2713 independent refiections were measured. The crystal belongs to space group $P \overline{4}$ with the lattice constants, $a=13.892(7)$ and $c=12.686(7) \AA$. The observed density indicates that four structure units of $\mathrm{C}_{21} \mathrm{H}_{22} \mathrm{O}_{7} \mathrm{Br}_{2} \cdot 1 / 2 \mathrm{Na} \cdot 2 \mathrm{H}_{2} \mathrm{O}$ are contained in a cell. The refinement of the structural parameters was carried out to an $R$ value of 0.077 by the block-diagonal least-squares method. The result confirmed the structure of MS-3 as that had been proposed on the basis of chemical studies.
\end{abstract}

MS-3, ${ }^{1,} \quad \mathrm{C}_{21} \mathrm{H}_{24} \mathrm{O}_{7}$, was isolated from a cultured broth of a mushroom, Stereum hirsutum, by screening studies on glyoxalase I inhibitor. MS-3 inhibits rat liver glyoxalase I competitively with the substrate ${ }^{2)}$ (the hemimercaptal adduct formed from methylglyoxal and glutathione) and exhibits inhibition ${ }^{1)}$ against the growth of Yoshida sarcoma cells in cell culture.

The structure of MS-3 was shown by chemical studies to be $3^{\prime}, 4^{\prime}$-dihydroxymethyl5 '- hydroxy - 6' - (3 - methyl - 2 - butenyl) - phenyl 2,4-dihydroxy-6-methyl benzoate. ${ }^{3}$ ' In order to confirm this chemical structure, a derivative was chosen for the X-ray structure determination. MS-3, brominated by N-bromosuccinimide (NBS), ${ }^{4,5}$ was crystallized as prisms. The crystal structure of this brominated compound has been determined by the heavy atom method.

\section{EXPERIMENTAL}

MS-3 was brominated by treatment with NBS in ether (ether was anhydrated with sodium) at $5^{\circ} \mathrm{C}$ for overnight. The brominated compound was separated by column chromatography of Sephadex LH-20 using methanol as developing solvent. NMR spectrum of this compound in $\mathrm{CD}_{3} \mathrm{OD}$ indicated that two aromatic protons ${ }^{33}$ at $\delta 6.26$ and 6.18 of MS-3 were exchanged with two bromine atoms. The crystals of the brominated compound grown from acetonebenzene solution were pale yellow prisms.

Diffraction data were obtained for the crystal with approximate dimensions of $0.10 \times 0.25 \times 0.20 \mathrm{~mm}$, on a Philips four-circle X-ray diffractometer using graphite monochromated CuKa radiation. Lattice constants were obtained by the least-squares refinement of the angular setting values for 12 reflections. Intensities were measured by the $\theta \sim 2 \theta$ scanning method at a scan speed of $4^{\circ} \theta \mathrm{min}^{-1}$. When the total counts during a single scan were less than $4 \times 10^{4}$, scanning was repeated twice. The background was measured at each end of the scan for half the total scan time. A total of 2713 independent reflections were measured within $78^{\circ} \theta$, of which 2220 were stronger than the $3 \sigma$ (Fo) level, and they were used for the subsequent structure determination. The density of the crystal was measured by the floatation method using the mixed solution of benzene and iodobenzene. From the observed value $\left(1.608 \mathrm{gcm}^{-3}\right)$, the weight of 592.4 daltons was calculated for the structure unit contained in an asymmetric unit, assuming four units were contained in a unit cell. However, the molecular weight calculated for dibromo-MS-3 was 546.2 daltons. During the structure determination, it was found that two sodium ions and eight water molecules were contained in the unit cell. An atomic absorption analysis showed that the crystal contained $2.06 \%$ (wt) sodium. The crystal data are given in Table I. 
Table I. Crystal Data

\begin{tabular}{ll}
$\mathrm{C}_{21} \mathrm{H}_{22} \mathrm{O}_{7} \mathrm{Br}_{2} \cdot 1 / 2 \mathrm{Na} \cdot 2 \mathrm{H}_{2} \mathrm{O}$, & $\mathrm{F} . \mathrm{W} .=593.7$ \\
space group $P \overline{4}$, & $Z=4$ \\
$a=13.892(7) \AA$ & $D_{m}=1.608 \mathrm{gcm}^{-1}$ \\
$c=12.686(7)$ & $D_{x}=1.611$ \\
$V=2448.2 \AA^{3}$ & \\
\hline
\end{tabular}

The crystal structure was determined by the heavy atom method. The locations of the two bromine atoms were determined by the Patterson method. The electron density distribution, synthesised by using the phase angles of the calculated structure factors for the two bromine atoms $(R=0.36)$, revealed the locations of almost all the atoms. Successive use of Fourier and difference Fourier syntheses, coupled with block-diagonal least-squares refinement, established the structure of the crystal. The refinement of the structural parameters was carried out by the block- diagonal least-squares method to an $R$ value of 0.077 . The final atomic parameters are listed in Table II. The weighting system adopted in the least-squares refinement was: $w=0$, when $F o=0 ; w=1$, when $F o \leq 20 ; \sqrt{w}=20 / F O$, when $F o>20$.

\section{RESULTS AND DISCUSSION}

The chemical structure proposed for MS-3 in the preceding paper ${ }^{3 /}$ has now been confirmed by the present structure determination. The bond lengths and angles are shown in Fig. 1. The standard deviations are estimated to be $0.011 \AA$ for $\mathrm{Br}-\mathrm{C}, 0.015 \AA$ for $\mathrm{C}-\mathrm{O}$, $0.018 \AA$ for $\mathrm{C}-\mathrm{C}$ bonds and about $1^{\circ}$ for $\mathrm{C}-\mathrm{C}-\mathrm{C}$ bond angles. However, some of the terminal atoms have very large anisotropic

Table II. Final Atomic Parameters $\left(\times 10^{4}\right)$

The temperature factors are of the form: $T=\exp \left[-\left(\beta_{11} \mathrm{~h}^{2}+\beta_{22} \mathrm{k}^{2}+\beta_{33} l^{2}+2 \beta_{12} \mathrm{hk}+2 \beta_{13} \mathrm{~h} l+2 \beta_{23} \mathrm{k} l\right)\right]$

\begin{tabular}{|c|c|c|c|c|c|c|c|c|c|}
\hline & $\mathrm{x}$ & $\mathrm{y}$ & $\mathrm{z}$ & $\beta_{11}$ & $\beta_{22}$ & $\beta_{33}$ & $\beta_{12}$ & $\beta_{13}$ & $\beta_{2 s}$ \\
\hline BR 1 & 3939 (1) & $11758(1)$ & $-117(1)$ & $116(1)$ & $57(1)$ & $61(1)$ & $-5(1)$ & $2(1)$ & 10( \\
\hline BR 2 & $3865(1)$ & $12050(1)$ & $4283(1)$ & $131(1)$ & ( 1$)$ & $(1)$ & $-9(1)$ & $-2(1)$ & $-17(1)$ \\
\hline C 1 & $3868(10)$ & $11150(8)$ & $1179(10)$ & $69(8)$ & ( 5$)$ & $3(7)$ & $0(5)$ & $-10(7)$ & $-6(5)$ \\
\hline $\mathrm{C}$ & 3894 (11) & $11740(8)$ & $2109(10)$ & $76(9)$ & $34(6)$ & $69(8)$ & $-5(6)$ & $3(8)$ & $-2(6)$ \\
\hline $\mathrm{C}$ & 3839 ( 9 ) & $11238(7)$ & $3075(10)$ & $60(7)$ & $32(5)$ & $71(8)$ & $-6(5)$ & $-4(6)$ & $-1(5)$ \\
\hline $\mathrm{C}$ & $3730(9)$ & $10252(7)$ & $3178(9)$ & $66(7)$ & $34(5)$ & $55(7)$ & $-6(5)$ & $6(6)$ & $-5(5)$ \\
\hline $\mathrm{C}$ & $3707(8)$ & $9696(7)$ & $2244(10)$ & $48(5)$ & $38(5)$ & $62(8)$ & $-8(4)$ & $6(6)$ & $2(5)$ \\
\hline $\mathrm{C}$ & $3806(8)$ & $10163(7)$ & $1247(10)$ & $54(6)$ & $41(5)$ & $60(7)$ & $-7(5)$ & $-5(6)$ & $-11(5)$ \\
\hline $\mathrm{O}$ & $3920(10)$ & $12664(6)$ & $2059(9)$ & $146(10)$ & $33(5)$ & $0(7)$ & $-3(5)$ & $-20(8)$ & $-2(4)$ \\
\hline $\mathrm{C}$ & $3710(12)$ & $9789(9)$ & $4263(11)$ & 107 (11) & $51(6)$ & $9(8)$ & $-15(7)$ & $15(9)$ & $2(7)$ \\
\hline $\mathrm{O}$ & $3858(7)$ & $9676(6)$ & 6) & $4(5)$ & $55(5$ & $9(5)$ & $-14(4)$ & $9(4)$ & $-14(4)$ \\
\hline C 10 & ( 8$)$ & $8678(8)$ & & $5(5)$ & $41(6)$ & ( & $-13(4)$ & $14(6)$ & $-9(6)$ \\
\hline O 11 & 35 & $8187(6)$ & & $90(7)$ & $42(4)$ & $9(7)$ & $-26(4)$ & $24(6)$ & $-22(5)$ \\
\hline O 12 & & ( 5$)$ & & $62(5)$ & $7(4)$ & $8(6)$ & $-11(3)$ & $4(4)$ & $-2(4)$ \\
\hline C 13 & $2852(9)$ & $7321(7)$ & & $63(7)$ & ( 5 ) & $60(8)$ & $-10(5)$ & $11(6)$ & $-3(5)$ \\
\hline C 14 & $3413(8)$ & $6565(8)$ & 3356 & $44(6)$ & 40( & (10) & $-9(5)$ & $6(7)$ & $-15(6)$ \\
\hline C 15 & $3055(8)$ & $5637(8)$ & 3392 & $51(6)$ & 5) & 8) & $-10(5)$ & $11(6)$ & $-8(5)$ \\
\hline C 16 & $2082(8)$ & $5485(8)$ & $3092(9)$ & $46(6)$ & ( 6 ) & $50(7)$ & $-4(5)$ & $5(5)$ & $-1(5)$ \\
\hline C 17 & $1533(8)$ & $6301(8)$ & 2803 (9) & $39(5)$ & $52(6)$ & $55(7)$ & $-6(4)$ & $6(5)$ & -4( \\
\hline C 18 & $1912(8)$ & $7223(8)$ & $2775(10)$ & $44(6)$ & $51(6)$ & $65(8)$ & $-4(4)$ & $0(6)$ & $8(6)$ \\
\hline O 19 & $591(5)$ & $6124(6)$ & $2540(8)$ & $37(4)$ & $55(4)$ & $92(7)$ & $-12(3)$ & $-13(4)$ & $6(5)$ \\
\hline C 20 & $1596(10)$ & 4508 ( 9) & $3053(10)$ & $69(8)$ & $51(6)$ & $58(8)$ & $-22(6)$ & $-3(6)$ & $1(6)$ \\
\hline O 21 & $1354(6)$ & $4226(6)$ & 2019 ( 7) & $70(5)$ & $48(5)$ & $73(6)$ & $-10(4)$ & $-13(5)$ & $-13(4)$ \\
\hline C 22 & $3670(10)$ & 4835 (9) & $3780(16)$ & $60(7)$ & $41(6)$ & $145(16)$ & $11(6)$ & $-17(10)$ & $-14(8)$ \\
\hline O 23 & $4156(9)$ & $4353(7)$ & $2981(16)$ & $89(8)$ & $49(5)$ & 240 (19) & $-2(5)$ & $26(11)$ & -17 (9) \\
\hline C 24 & $1289(11)$ & $8067(10)$ & $2436(18)$ & $73(9)$ & $53(7)$ & $141(19)$ & $4(6)$ & $11(11)$ & $5(10)$ \\
\hline C 25 & $451(13)$ & $8180(15)$ & $3143(26)$ & $51(9)$ & $92(12)$ & $279(36)$ & $9(8)$ & $30(15)$ & $18(18)$ \\
\hline C 26 & $-473(19)$ & $8434(17)$ & $2745(44)$ & $108(18)$ & $97(15)$ & $443(78)$ & $16(13)$ & $78(33)$ & $74(32)$ \\
\hline C 27 & $-606(22)$ & $8476(22)$ & $1511(35)$ & $135(23)$ & $155(23)$ & $280(44)$ & $-6(18)$ & $23(28)$ & $-24(28)$ \\
\hline C 28 & $-1210(22)$ & $8573(31)$ & $3468(65)$ & $145(22)$ & $256(39)$ & $778(128)$ & $123(24)$ & $177(47)$ & $165(60)$ \\
\hline NA & $0(0)$ & $5000(0)$ & $1201(6)$ & 49 ( 3$)$ & $65(4)$ & $64(5)$ & $-11(3)$ & $0(0)$ & $0(0)$ \\
\hline OW1 & $3686(13)$ & $4471(12)$ & $-976(16)$ & $152(13)$ & $129(11)$ & $143(16)$ & $6(10)$ & $29(13)$ & $28(12)$ \\
\hline OW2 & $3118(14)$ & 4054 (14) & $986(17)$ & $181(15)$ & $181(14)$ & $157(19)$ & $113(12)$ & $60(15)$ & $58(15)$ \\
\hline
\end{tabular}




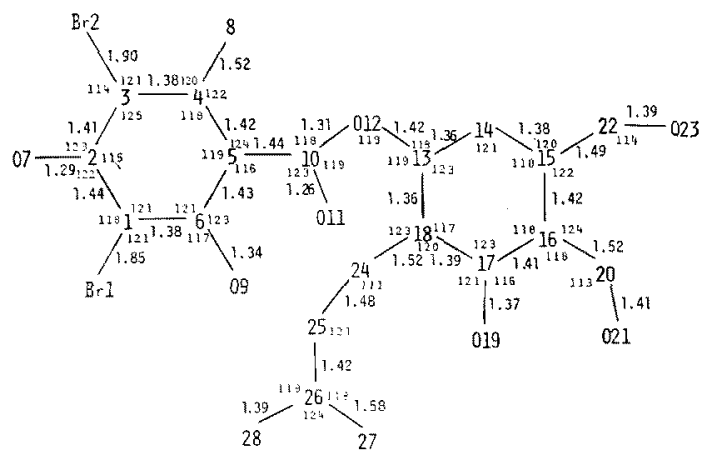

Fig. 1. Bond Lengths and Angles.

temperature factors as shown below and the standard deviations of the bond lengths and bond angles involving these atoms may exceed $0.07 \AA$ and $4^{\circ}$, respectively. The anisotropic temperature factors of $\mathrm{C} 28, \mathrm{C} 27, \mathrm{C} 26, \mathrm{C} 25$ and $\mathrm{O} 23$ are extremely large; one of their principal axes of vibration has three to ten times larger mean square displacements of atoms than those of other atoms.

There seems to be no anomalous feature in bond lengths and angles except for those involving above-mentioned atoms. The sodium ion is situated on the diad axis and is coordinated to six oxygen atoms of four molecules. It is bound to the O19 and O21 hydroxyl oxygen atoms of a molecule completing a chelate ring. Two such chelate rings share a sodium ion around the diad axis. The geometry of the coordination can be seen in Fig. 2. To illustrate the conformation of the molecule,

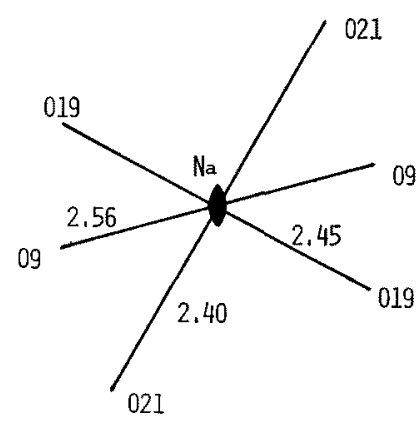

FIG. 2. Geometry of the Coordination of Sodium Ion.

TABle III. Torsion Angles

\begin{tabular}{lr}
\hline $\mathrm{C} 4-\mathrm{C} 5-\mathrm{C} 10-\mathrm{O} 12$ & $7^{\circ}$ \\
$\mathrm{C} 10-\mathrm{O} 12-\mathrm{C} 13-\mathrm{C} 18$ & -79 \\
$\mathrm{C} 16-\mathrm{C} 15-\mathrm{C} 22-\mathrm{O} 23$ & 89 \\
$\mathrm{C} 17-\mathrm{C} 16-\mathrm{C} 20-\mathrm{O} 21$ & 66 \\
$\mathrm{C} 17-\mathrm{C} 18-\mathrm{C} 24-\mathrm{C} 25$ & 60 \\
$\mathrm{C} 24-\mathrm{C} 25-\mathrm{C} 26-\mathrm{C} 27$ & 7 \\
\hline
\end{tabular}

some torsion angles are listed in Table III. The two benzene rings linked by an ester bond form an angle of about $105^{\circ}$ to each other. The twisting occurs mainly at $\mathrm{O} 12-\mathrm{C} 13$ (C10$\left.\mathrm{O} 12-\mathrm{Cl} 3 \mathrm{C} 18=79^{\circ}\right)$. The orientations of the $\mathrm{O} 12-\mathrm{C} 10, \mathrm{C} 20-\mathrm{O} 21, \mathrm{C} 22-\mathrm{O} 23$ and $\mathrm{C} 24$ $\mathrm{C} 25$ bonds with respect to the benzene ring are staggered; they do not lie on the plane of the benzene ring and the torsion angles about the bonds which connect these bonds to the benzene ring range from $60^{\circ}$ ( $\mathrm{C} 17-$ $\mathrm{C} 18-\mathrm{C} 24-\mathrm{C} 25)$ to $89^{\circ}(\mathrm{C} 16-\mathrm{C} 15-\mathrm{C} 22-\mathrm{O} 23)$.

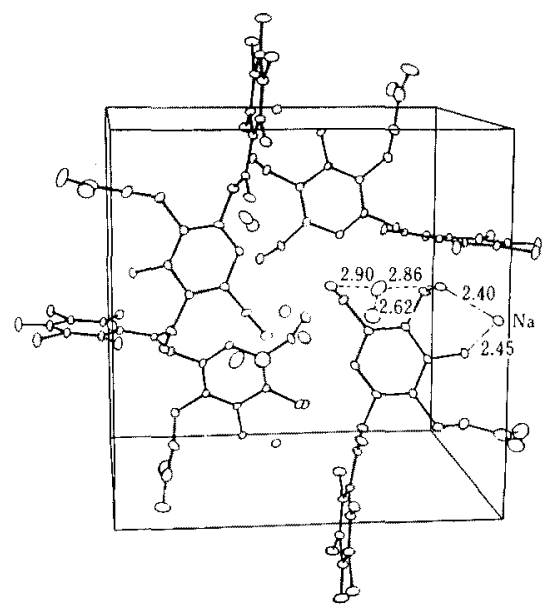

Fig. 3. Structure of the Crystal Drawn by the ORTEP Program. 
The carbonyl group of the 2,4-dihydroxy-6methyl benzoate moiety twists only by a small angle $\left(7^{\circ}\right)$ to the benzene ring as usually seen in benzene carboxylic acids. The structure of the crystal is illustrated in Fig. 3 by a perspective stereoscopic-drawing viewed along the $c$ axis. The molecules are bound together through the sodium ions as mentioned before, and they are also linked by hydrogen bonds through the water molecules.

\section{REFERENCES}

1) S. Kurasawa, T. Takeuchi and H. Umezawa, Agr. Biol. Chem., 39, 2003 (1975).

2) S. Kurasawa, T. Takeuchi and H. Umezawa, ibid., 40, 567 (1976).

3) S. Kurasawa, H. Naganawa, T. Takeuchi and H. Umezawa, ibid., 39, 2009 (1975).

4) C. Djerassi, Chem. Rev., 43, 275 (1948).

5) K. H. Dudley and H.W. Miller, Tetrahedron Lett., $1968,571$.

6) C. K. Johnson, ORTEP Report ORNL-3794, Oak Ridge National Laboratory, Oak Ridge, Tennessee, U.S.A. (1965). 